\title{
MATERIAL EDUCATIVO GAMIFICADO PARA LA ENSEÑANZA-APRENDIZAJE DE CONCEPTOS DE ECOLOGÍA EN ESTUDIANTES DE EDUCACIÓN MEDIA
}

\section{GAMIFIED EDUCATIONAL MATERIAL FOR THE TEACHING-LEARNING OF ECOLOGICAL CONCEPTS IN HIGH SCHOOL STUDENTS}

\section{Lydy Yalile Ducuara Amado}

\section{Ariel Adolfo Rodríguez Hernández ${ }^{1}$}

Jorge Armando Niño Vega ${ }^{2}$

Flavio Humberto Fernández Morales ${ }^{3}$

Universidad Pedagógica y Tecnológica

de Colombia, Duitama, Colombia.

$1 \quad$ Magister en software libre, Ingeniero en sistemas con énfasis en software, Docente investigador, Universidad Pedagógica y Tecnológica de Colombia. ariel.rodriguez@ uptc.edu.co ORCID ID: https://orcid.org/0000-0003-1906$\underline{7734}$

2 Magíster en TIC Aplicadas a las Ciencias de la Educación, Licenciado en Tecnología, Docente investigador, Universidad Pedagógica y Tecnológica de Colombia. Jorge. ninovega@gmail.com ORCID ID: https://orcid.org/0000$\underline{0001-7803-5535}$

3 Doctor en Ingeniería Electrónica, Ingeniero Electrónico, Docente Investigador, Universidad Pedagógica y Tecnológica de Colombia. flaviofm1@gmail.com ORCID ID: https://orcid.org/0000-0002-8970-7146

\section{RESUMEN}

Este trabajo presenta el desarrollo de un material educativo gamificado para orientar conceptos de ecología en educación media. La población correspondió a 30 estudiantes de grado décimo y 4 docentes, de una institución educativa colombiana. Los contenidos se crearon de acuerdo a los lineamientos del Ministerio 
de Educación de Colombia, atendiendo las problemáticas ambientales que se presentan a nivel mundial. La validación del material educativo por parte de los estudiantes, evidencia la efectividad de la gamificación y las TIC en la atención, disposición para el aprendizaje y mejoramiento del ambiente de aula. Los docentes consideran el material educativo apropiado al nivel de enseñanza, y pertinente para el trabajo de clase. Se concluye que el desarrollo de un material de este tipo, requiere de una planeación en base a las necesidades de los educandos, al modelo pedagógico y disponibilidad de los recursos tecnológicos institucionales.

PALABRAS CLAVE: Material educativo gamificado, TIC, ciencias naturales, ecología.

\section{ABSTRACT}

This work presents the development of a gamified educational material to guide ecology concepts in secondary education. The population corresponded to 30 tenth grade students and 4 teachers from a Colombian educational institution. The contents were created according to the guidelines of the Colombian Ministry of Education, addressing the environmental problems that arise worldwide. The validation of the educational material by the students shows the effectiveness of gamification and ICT in attention, readiness for learning and improvement of the classroom environment. Teachers consider the educational material appropriate to the level of teaching, and relevant for class work. It is concluded that the development of a material of this type requires planning based on the needs of the students, the pedagogical model and availability of institutional technological resources.

KEYWORDS: Gamified educational material, ICT, natural sciences, ecology.

\section{INTRODUCCIÓN}

Hoy en día se evidencian graves daños al medio ambiente, generados por relaciones humanas de consumo y explotación de recursos naturales, con el propósito de satisfacer unas necesidades que superan la capacidad de carga del planeta (Rivera-Guerrero, Gualdrón-Guerrero \& TorresChávez, 2020). Según Lozano-Guzmán, Bosque-Suárez, y Osorio-Abad (2019), el inmenso conocimiento del ser humano no ha sido suficiente para sensibilizarse sobre los impactos al medio ambiente, y para subsanar los daños que ha ocasionado. Para SarmientoMedina (2013), las acciones individuales y colectivas de décadas atrás, han ocasionado la alteración del sistema tierra, y el hombre en su ambición económica, se constituyó en un saqueador del planeta.

Aranda-Sánchez (2015), expresa que la incapacidad de responder a la crisis ecológica, se debe al desconocimiento de las intrincadas relaciones que se establecen entre los organismos del ecosistema. En este sentido, Hernández-Díaz (2014), señala que la escuela, es uno de los principales motores, para generar una mentalidad ecológica, en contraposición a la visión consumista y de carácter irresponsable que impera en la actualidad.

Malacalza (2013), considera a la ecología como una ciencia dedicada al estudio de los niveles de organización de los seres vivos, como las poblaciones y comunidades, señalando que cada día se preocupan más los ecólogos, por investigar sobre los impactos ambientales del ser humano en los ecosistemas. En Colombia, la Ley General de Educación (Ley 115, 1994), señala en el capítulo 1, artículo 14, parágrafo c, como obligatoria la enseñanza de la protección del ambiente, la ecología y la preservación de los recursos naturales, de conformidad con lo establecido en el artículo 67 de la Constitución Política (Sepúlveda-Gallego, 2014). 
Lo anterior indica la importancia de la enseñanza de la ecología en la escuela, a través de propuestas pedagógicas actualizadas y pertinentes al contexto de los estudiantes (NiñoVega \& Fernández- Morales, 2019; López-Gaitán et al, 2018). Si bien existen gran cantidad de materiales educativos mediados por Tecnologías de la Información y la Comunicación (TIC), en áreas como: matemáticas, física o biología, se presenta carencia de este tipo de materiales para el aprendizaje de la ecología (JiménezEspinosa, 2019; Ruiz-Macías \& Duarte, 2018; Angarita-López, Fernández-Morales \& Duarte, 2018).

En este documento se presenta el desarrollo de un material educativo gamificado, para la enseñanza de conceptos de ecología en educación media. A continuación, se presenta el marco teórico relacionado con la gamificación, junto con la metodología utilizada en la investigación. Dentro de los resultados, aparecen: la estructura del material educativo gamificado, los contenidos trabajados, la página web elaborada, y finalmente la validación del material por parte de estudiantes y docentes.

\section{MARCO TEÓRICO Y METODOLOGÍA}

\subsection{Enseñanza de la ecología y gamificación}

Carceller-Cobos (2016), menciona que, así como la tecnología ha derivado en problemas ambientales, de igual modo la tecnología permite dar soluciones, indicando que las aplicaciones móviles relacionadas con la ecología, pretenden concienciar al público sobre los impactos a la naturaleza, para mejorar las condiciones de vida del ser humano. Para Beltrán-Salvo (2016), un podcast educativo sirve como herramienta para generar ciudadanos conscientes de la relación hombre-naturaleza, dando un lugar preponderante a la ecología en la educación.

En el trabajo de Lozano-Cruz y Moreno-Baquero (2014), se menciona la eficacia de un aula virtual, realizada para la enseñanza de la ecología en los niveles de básica secundaria y media, la cual se diseñó teniendo en cuenta los estándares básicos de competencias en ciencias naturales. Experiencias similares se han reportado en otras áreas del conocimiento, destacando la importancia de vincular las nuevas tecnologías en los diversos niveles educativos (HernándezGil \& Jaramillo-Gaitán, 2020; Avella-lbáñez, Sandoval-Valero \& Montañez-Torres, 2017).

El término gamificación proviene del vocablo inglés gamification, que en español es sinónimo de ludificación, juguetización y jueguificación, de tal manera que hace alusión a la utilización del juego (Valda-Sánchez \& Arteaga-Rivero, 2015; Vargas-Vargas et al, 2020). Toda, Da Silva y Isotani (2017), manifiestan que la utilización de la gamificación se ha extendido en el ámbito escolar, por sus efectos positivos sobre la responsabilidad de los educandos en las actividades que se les plantean. Además, Palanca-Climente y Ramos-Castillo (2018), sostienen que, desde la neuroeducación, se ve a la gamificación como una estrategia para incidir en el comportamiento del educando, pues combina conocimientos y emociones.

\subsection{Metodología}

Este estudio se realizó dentro de un enfoque de investigación cuantitativo, ya que se basó en la recolección de datos numéricos con el fin de conocer el nivel de aceptación que tuvieron los estudiantes y expertos frenteal material educativo gamificado (Ordóñez-Ortega, Gualdrón-Pinto \& Amaya-Franky, 2019). El alcance de la investigación es exploratorio, debido a que se identifica la problemática a resolver, se diseña y desarrolla el material educativo y se valida por parte de usuarios y expertos, con el fin de comprobar la funcionalidad del material como ayuda didáctica (Bernate et al., 2020). 
La investigación se adelantó en el Instituto Técnico Santo Tomás de Aquino, ITSA, ubicado en la ciudad de Duitama, Boyacá.

La población objeto de estudio correspondió a los 132 estudiantes del grado décimo, teniendo en cuenta que en este nivel se deben orientar contenidos alusivos a ecología y medio ambiente. La muestra se seleccionó por conveniencia, correspondiendo a los 30 estudiantes del grupo 1002 de la institución educativa. Igualmente, se contó con la colaboración de 4 docentes, a saber: 1 docente del área de tecnología e informática y 3 docentes del área de ciencias naturales, quienes hicieron la validación del material educativo desarrollado.

La metodología para: el diseño, desarrollo, aplicación y validación del material educativo gamificado, fue la siguiente:

Etapa 1. Diseño del material educativo gamificado: teniendo en cuenta los estándares básicos de competencias de ciencias naturales para grado décimo, se establecen las unidades que van dentro del material educativo, al igual que las actividades para la evaluación del aprendizaje de cada estudiante.

Etapa 2. Desarrollo del material educativo: se hace la selección de la interfaz para el montaje de contenidos, se diagrama la organización de los mismos, se elaboran los juegos y las actividades de afianzamiento.

Etapa 3. Aplicación de la estrategia: se realiza una prueba piloto con la población objeto, para establecer la funcionalidad del material desarrollado.

Etapa 4. Validación de la estrategia: se realiza la aplicación de una encuesta de satisfacción para los estudiantes y una matriz de evaluación o juicio de expertos, dirigido a cuatro docentes de la institución.

\section{RESULTADOS Y DISCUSIÓN}

\subsection{Contenidos del material educativo gamificado}

EI ITSTA toma como pilares metodológicos las teorías del modelo constructivista y de la pedagogía activa (Garzón-Saladen \& RomeroGonzález, 2018). De acuerdo con ello, y teniendo en cuenta los lineamientos curriculares del Ministerio de Educación Nacional de Colombia, MEN (2017), para la orientación de conceptos de ecología en educación media, se seleccionaron cinco unidades de estudio:

i) ¿Qué es un Ecosistema? En esta unidad se presentan las generalidades sobre los ecosistemas, conceptos básicos, se incluye un mapa conceptual de los factores abióticos, imágenes y un video de resumen. Como actividad interactiva de aprendizaje, se plantea un desafío desarrollado en Power point en el cual se van presentando preguntas para que el estudiante avance, dando oportunidad de contestar nuevamente, al final aparece el puntaje obtenido, siempre se da la posibilidad de mejoramiento. Como actividad de afianzamiento se propone la elaboración de un póster sobre la temática, en la herramienta canva.

ii) Tipos de Ecosistemas: se presentan las clases de ecosistemas de acuerdo al medio en el que se desarrollan los organismos, aparecen imágenes alusivas al tema, un video complementario de los biomas del mundo y un video resumen de la temática. Como actividad de aprendizaje, se presenta un crucigrama sobre la temática elaborado en educaplay, con límite de tiempo para su desarrollo. Como tarea de afianzamiento se propone la realización de un mentefacto conceptual sobre la temática, utilizando la herramienta GoCongr.

iii) Tipos de Ecosistemas Colombianos: se presentan las generalidades de los principales ecosistemas terrestres y acuáticos con los 
que cuenta Colombia, haciendo énfasis en la megadiversidad de nuestro país. Se emplean imágenes sobre la temática y un video complementario, referente a la influencia del ser humano sobre los mismos. La actividad de aprendizaje consiste en un concéntrese elaborado en educaplay, para emparejamiento de dibujo y definición, con límite de tiempo; como tarea de afianzamiento se propone la lectura del texto de Villafrades-Torres (2017).

iv) Relaciones Ecológicas: en esta unidad se presentan los tipos de relaciones entre los organismos de la misma y de diferente especie, planteando la importancia de cada individuo en el mantenimiento del equilibrio ecosistémico. Como actividad de aprendizaje se presenta un desafío elaborado en Quizizz, con una serie de preguntas sobre la temática, sin límite de tiempo y con la posibilidad de presentarse en diferentes oportunidades para mejorar el puntaje; como tarea de afianzamiento se propone la elaboración de una historieta en parejas, utilizando la herramienta Canva.

v) Flujo de Materia y Energía de los Ecosistemas: se presentan los diferentes niveles tróficos del ecosistema, señalando la definición de cada uno. Como actividad de aprendizaje, se plantea un desafío elaborado en quizizz para desarrollar en grupos de cinco estudiantes, sin posibilidad de presentar nuevamente; como tarea de afianzamiento se estableció la realización de un escrito en grupos, en el que se relacionará la temática con la cotidianidad.

\subsection{Desarrollo del material educativo gamificado}

Se realizó el montaje de los contenidos en la web y en la plataforma Wix, debido a características como: la facilidad de uso, la adaptabilidad de los contenidos para visualizarse en distintos sistemas operativos y diferentes navegadores de internet (Mercado-Ramos, Zapata \& Ceballos, 2015; Niño-Vega et al, 2017). Asimismo, Wix da la posibilidad de acceder a diferentes plantillas, es posible realizar ajustes y modificaciones que se actualizan de forma inmediata, y ofrece un dominio gratis (Niño-Vega, Fernández-Morales \& Duarte, 2019). Teniendo en cuenta estas particularidades, se realizó el montaje de los contenidos en Wix, con la dirección web: https:// ecologygamificacio.wixsite.com/2019

En la figura 1, se presenta el mapa del sitio de la página web. En ella se resalta el apartado: Nuestro propósito, donde aparece el nivel al que va dirigido el material educativo, un recuento de los contenidos a trabajar, el objetivo general, los objetivos específicos, y los estándares básicos de competencias previstos para grado décimo. En la segunda sección, llamada Inicio, aparecen los botones de acceso a las unidades de trabajo, la cartilla en archivo $P D F$, un glosario y los botones de acceso a la sección El Planeta te necesita, en la que se presentan videos sobre impacto ambiental y reflexiones sobre ésta situación. El botón Demostrando nuestros aprendizajes, direcciona a los estudiantes hacia las tareas escolares de cada unidad, con los objetivos a alcanzar y el espacio para compartir sus trabajos; también se pueden realizar el comentario a las actividades de los demás compañeros. En ésta sección también se encuentra la herramienta de chat para comunicación del estudiante con el docente, junto con un apartado donde se incluye a los estudiantes participantes. 
A

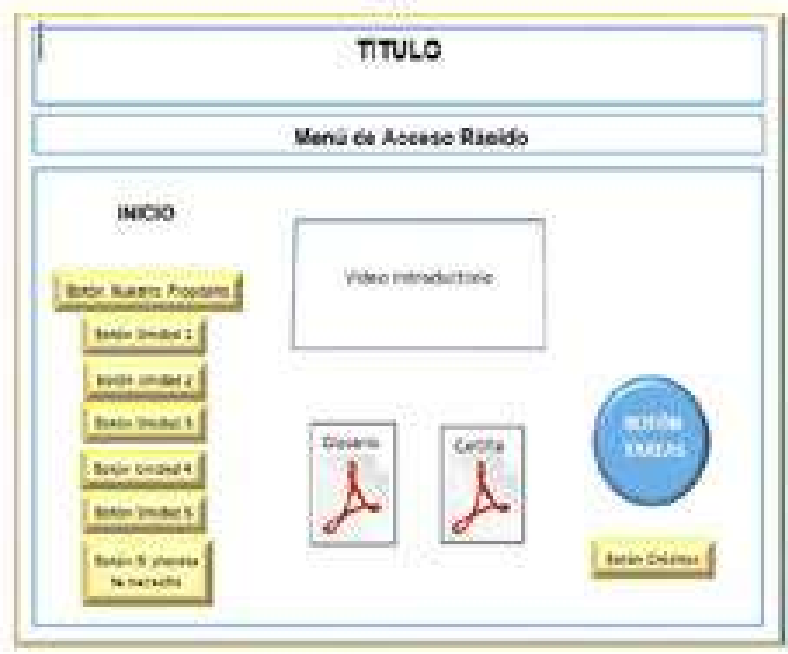

B

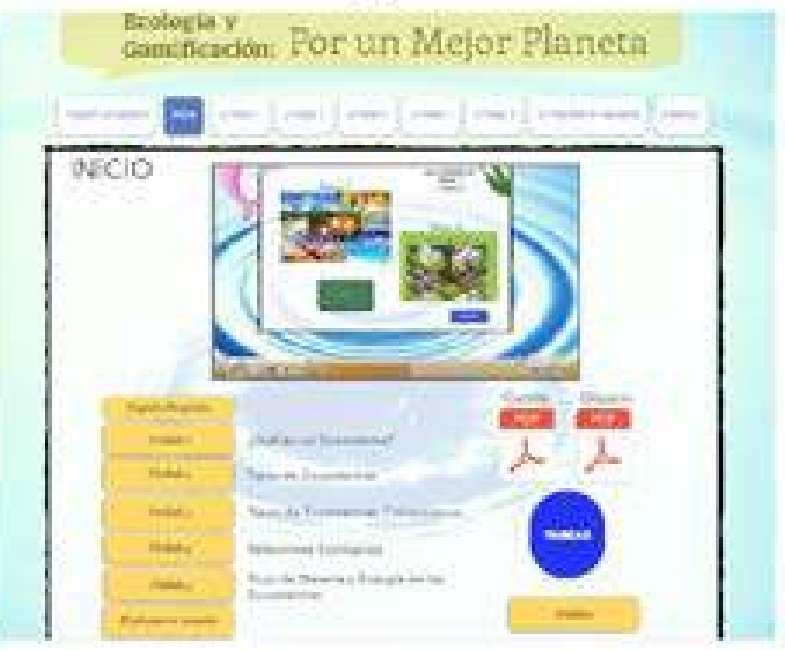

Figura 1. Diseño de la página web.

En cuanto a los juegos desarrollados, por unidad temática, presentan las siguientes particularidades: en la unidad 1 , el juego elaboradoen powerpoint, contienediez preguntas donde se busca que el estudiante identifique la respuesta en la que hay una contradicción con respecto al enunciado. En el juego aparecen: acertijos, jeroglíficos y adivinanzas, junto con la tabla de resultados, donde el estudiante verifica las preguntas que contestó correctamente y las incorrectas, obteniendo un puntaje que puede mejorar ejecutando nuevamente el juego.

El juego elaborado en educaplay para la Unidad 2, consiste en un crucigrama de diez interrogantes, con un tiempo límite de 15 minutos y se da posibilidad de mejorar la puntuación. El juego elaborado en Educaplay para la Unidad 3, presentan 10 imágenes que el estudiante relacionará con un pequeño fragmento. Se da un límite de tiempo de cinco minutos y la oportunidad de mejorar el puntaje. Es importante destacar que al final el juego presenta las respuestas acertadas, de modo que el estudiante realiza una realimentación de la información.

El juego elaborado en Quizizz para la Unidad 4, contiene 10 preguntas sobre la temática. El estudiante tiene la posibilidad de ejecutar el juego las veces que desee para mejorar su puntuación, junto con un espacio para recibir realimentación de las respuestas acertadas. EI juego elaborado en Quizizz para la Unidad 5, contiene 10 preguntas y está planteado para desarrollar en grupo de trabajo. La figura 2 presenta algunos de los juegos elaborados para la página web. 


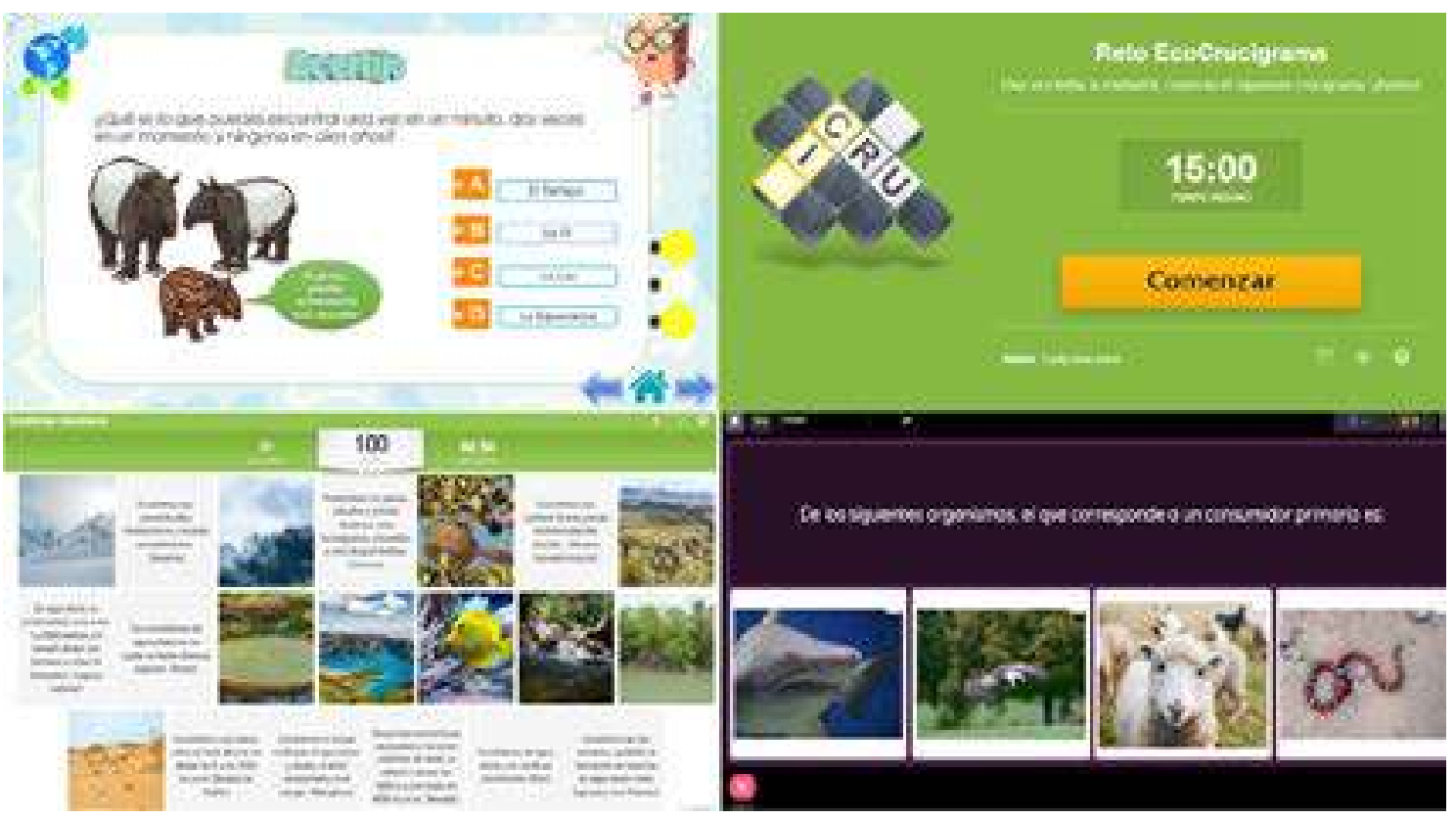

Figura 2. Juegos elaborados para la página web.

\subsection{Validación de la herramienta}

\subsubsection{Validación de los estudiantes}

El nivel de aceptación de la estrategia por parte de los 30 estudiantes participantes en la experiencia, se estableció a través de una encuesta de satisfacción. La encuesta se compone de 9 preguntas, valoradas bajo una escala tipo Likert, ver tabla 1.

Tabla 1. Resultados de la encuesta de satisfacción de estudiantes.

\begin{tabular}{|l|c|c|c|c|c|}
\hline \multicolumn{1}{|c|}{ Pregunta } & $\begin{array}{c}\text { Totalmente } \\
\text { de acuerdo }\end{array}$ & $\begin{array}{c}\text { De } \\
\text { acuerdo }\end{array}$ & Neutral & $\begin{array}{c}\text { En } \\
\text { desacuerdo }\end{array}$ & $\begin{array}{c}\text { Totalmente en } \\
\text { desacuerdo }\end{array}$ \\
\hline $\begin{array}{l}\text { La navegación en la } \\
\text { página es fácil. }\end{array}$ & 16 & 12 & 2 & 0 & 0 \\
\hline $\begin{array}{l}\text { La página web y las } \\
\text { unidades que allí se } \\
\text { presentan son de } \\
\text { utilidad. }\end{array}$ & 9 & 19 & 2 & 0 & 0 \\
\hline $\begin{array}{l}\text { El diseño de la página } \\
\text { web es muy agradable. }\end{array}$ & 14 & 12 & 4 & 0 & 0 \\
\hline $\begin{array}{l}\text { ¿Crees que los juegos } \\
\text { realizados ayudan a } \\
\text { reforzar las temáticas } \\
\text { trabajadas en cada } \\
\text { unidad? }\end{array}$ & 17 & 13 & 0 & 0 & 0 \\
\hline
\end{tabular}




\begin{tabular}{|c|c|c|c|c|c|}
\hline $\begin{array}{l}\text { En cuanto a la lectura } \\
\text { en medio digital e } \\
\text { impreso ¿consideras } \\
\text { que la página web } \\
\text { es una excelente } \\
\text { estrategia para evitar } \\
\text { el uso de papel } \\
\text { ayudando al medio? }\end{array}$ & 16 & 13 & 1 & 0 & 0 \\
\hline $\begin{array}{l}\text { Consideras que al } \\
\text { utilizar la página } \\
\text { web durante las } \\
\text { clases, ¿disminuyó la } \\
\text { utilización por parte } \\
\text { de tus compañeros } \\
\text { de clase, de celulares } \\
\text { u otros equipos } \\
\text { que distraen de los } \\
\text { propósitos de la } \\
\text { docente? }\end{array}$ & 7 & 18 & 5 & 0 & 0 \\
\hline $\begin{array}{l}\text { ¿Crees que la página } \\
\text { web motiva la lectura } \\
\text { y promueve hábitos } \\
\text { lectores? }\end{array}$ & 9 & 16 & 5 & 0 & 0 \\
\hline
\end{tabular}

Datos recolectados en campo (Fuente: Elaboración Propia).

Los resultados de la tabla 1 indican que el material educativo gamificado, logró un alto nivel de aceptabilidad por parte de los estudiantes, ya que: el diseño, la interfaz, la operabilidad que tiene la página web y los recursos digitales presentados fueron de su agrado. Se destaca que todos los estudiantes manifestaron estar de acuerdo y totalmente de acuerdo con los juegos educativos, ya que les permiten reforzar las temáticas propuestas en las diferentes unidades. A la pregunta sobre la dificultad de los juegos, a 4 estudiantes les pareció muy fácil, a 9 estudiantes les pareció fácil, a 16 estudiantes no les pareció ni fácil ni difícil, y tan solo 1 estudiante indicó que le parecieron difíciles los desafíos presentados. En cuanto a la satisfacción sobre los conocimientos alcanzados a partir de las unidades de la página web, tan solo 1 estudiante indicó que no se encuentra satisfecho, 12 estudiantes mantuvieron una posición neutral,
14 estudiantes afirmaron estar muy satisfechos, y 3 estudiantes mencionaron estar totalmente satisfechos.

\subsubsection{Validación por expertos}

La validación de la página web por parte de expertos, fue realizada por cuatro docentes de la Institución: un docente de la asignatura de tecnología e informática $\left(E_{1}\right)$, y por tres docentes de ciencias naturales $\left(E_{2}, E_{3}\right.$ y $\left.E_{4}\right)$. El instrumento utilizado para la valoración de la estrategia educativa gamificada, fue una matriz adaptada de la herramienta de evaluación de la Calidad de Ios Objetos de Aprendizaje, CODA, propuesta por Fernández-Pampillón, Domínguez-Romero y Armas-Ranero (2012).

La matriz de valoración presenta cinco criterios, a saber: objetivos y coherencia, calidad de contenidos, acceso y uso, motivación y diseño. 
En lo referente a la escala de valoración para medir cumplimiento, se tomaron valores de 1 a 4 , donde 4 corresponde al ítem se cumple plenamente y 1 a no se cumple. Los hallazgos de la aplicación el instrumento, aparecen en la tabla 2.

Tabla 2. Validación de la página web por expertos

\begin{tabular}{|c|c|c|c|c|c|}
\hline Criterio & Descripción & E1 & E2 & E3 & E4 \\
\hline $\begin{array}{l}\text { Objetivos y } \\
\text { coherencia }\end{array}$ & $\begin{array}{l}\text { Se especifica a quienes va dirigida la página } \\
\text { web, se presentan con claridad los objetivos } \\
\text { y se señalan los aprendizajes esperados. }\end{array}$ & 3 & 4 & 4 & 4 \\
\hline $\begin{array}{l}\text { Calidad y } \\
\text { contenidos } \\
\end{array}$ & $\begin{array}{l}\text { El contenido es claro, actualizado y acorde } \\
\text { al nivel de los estudiantes. }\end{array}$ & 3 & 4 & 4 & 4 \\
\hline Acceso y uso & $\begin{array}{l}\text { Hay facilidad en el ingreso a la página, } \\
\text { se especifica la forma de utilización, se } \\
\text { encuentran los contenidos con rapidez, y } \\
\text { no se presenta ningún botón que tenga } \\
\text { dificultad. }\end{array}$ & 3 & 4 & 3 & 3 \\
\hline Motivación & $\begin{array}{l}\text { Los contenidos se presentan de forma } \\
\text { atractiva, y se mantiene el interés a través } \\
\text { de las actividades que allí se encuentran. }\end{array}$ & 3 & 4 & 4 & 4 \\
\hline Diseño & $\begin{array}{l}\text { Los contenidos se presentan de forma } \\
\text { organizada, los colores son adecuados, y los } \\
\text { videos e imágenes utilizadas son de calidad. }\end{array}$ & 3 & 4 & 4 & 4 \\
\hline
\end{tabular}

Fuente: elaboración propia.

En los resultados de la tabla 2, se evidencia que la página web y los recursos educativos digitales cumplen con los diferentes criterios, según los expertos. Sin embargo, se presenta un menor cumplimiento en lo que respecta a acceso y uso, puesto que los docentes E1, E3 y E4, manifestaron un nivel de cumplimiento de 3. Además, el docente de informática (E1), califica todos los criterios con un nivel de cumplimiento de 3; es decir, que se cumple en alto grado pero que se deben hacer algunos ajustes, los cuales se efectuaron en la versión final del material educativo.

\subsection{Discusión}

La mayoría de los trabajos sobre gamificación revisados para este estudio, se han aplicado en educación básica, en asignaturas como: matemáticas, español, inglés, física y química, así como en educación superior (Orhan-Göksün \& Gürsoy, 2019; Corchuelo-Rodriguez, 2018; Zepeda-Hernández, Abascal-Mena, \& LópezOrnelas, 2016). Sin embargo, la aplicación de esta estrategia en educación media, es escasa, y para enseñanza-aprendizaje de la ecología, prácticamente inexistente.

En este sentido, el diseño de la página web y los recursos educativos digitales propuestos en esta investigación, permitieron generar un material educativo gamificado, orientado a la enseñanza de conceptos de ecología a estudiantes de educación media. Esto se debe a la utilización de herramientas tecnológicas versátiles, intuitivas y adaptables, como: Wix, Educaplay, 
Quizzy y Pixabay, unidas a programas, como: Power Point, Spark y Screencast o Matic.

La socialización del material educativo ante los expertos de la institución, fue un proceso enriquecedor. Gracias a sugerencias, como: la inclusión de actividades de reflexión con sentido crítico frente a la responsabilidad del ser humano en las problemáticas medioambientales, el manejo de imágenes y mejora de la estética de la página web, se pudo poner a punto un material educativo relevante para la institución.

La aceptación de los juegos por parte de los estudiantes fue elevada, fomentando un escenario de motivación por aprender temáticas relativas al medio ambiente. Esto a pesar de ser estudiantes de nivel superior, grado décimo en este caso. Resultados similares han sido reportados por investigadores como CarriónSalinas (2017), Alcívar-Alcívar (2020) y PeláezLópez y otros (2020) destacando la necesidad de identificar las necesidades curriculares y pedagógicas, para que la implementación en el aula de los materiales educativos gamificados, sea exitosa.

\section{CONCLUSIONES}

El desarrollo del material educativo gamificado, requirió de una planeación basada en: las necesidades de los educandos, el modelo pedagógico y disponibilidad de los recursos tecnológicos institucionales. Igualmente, se tuvieron en cuenta los momentos de una clase, como: la exploración, la estructuración, práctica, transferencia y valoración, según la guía de fortalecimiento curricular.

El material contó con una página web alrededor de la temática de ecología, y se apoyó en: imágenes, videos, texto, audios y juegos. Estos elementos se orientan a motivar y fomentar el gusto por el aprendizaje, promoviendo valores de respeto y conservación de los ecosistemas.
La validación por expertos se basó en la matriz CODA, evidenciando un elevado cumplimiento de criterios de diseño y uso. La encuesta de satisfacción aplicada a los estudiantes, mostró su aceptación en lo referente a utilidad e importancia de los contenidos, así como en cuanto a la facilidad de uso. Igualmente, fue notoria la motivación de los estudiantes, evidenciada en el uso de los dispositivos móviles en el aprendizaje de los conceptos de ecología.

Se concluye que la utilización de material educativo gamificado no solo impacta a los educandos, sino al docente en sí mismo, dado que propicia el desarrollo de habilidades olvidadas, en cuanto a capacidad de innovación, venciendo los temores sobre la utilización de las nuevas tecnologías en la educación.

\section{REFERENCIAS BIBLIOGRÁFICAS}

Alcívar-Alcívar, A. M. (2020). Usos educativos de las principales redes sociales: el estudiante que aprende mientras navega. Revista Científica Ecociencia, 7, 1-14. Recuperado de: http://revistas.ecotec. edu.ec/index.php/ecociencia/article/ view/294

Angarita-López, R. D., Duarte, J. E., \& FernándezMorales, F. H. (2018). Desarrollo de un MEC para la creación de cultura ciudadana sobre el uso del recurso hídrico en estudiantes de educación básica. Revista Espacios, 39 (15), 19. Recuperado de: http://www.revistaespacios.com/ a18v39n15/18391519.html

Aranda-Sánchez, J. M. (2015). La alfabetización ecológica como nueva pedagogía para la comprensión de los seres vivientes. Luna Azul, (41), 365-384. Recuperado de: http://www.scielo.org.co/pdf/luaz/n41/ n41a20.pdf

Avella-lbáñez, C. P., Sandoval-Valero, E. M., \& Montañez-Torres, C. (2017). Selección 
de herramientas web para la creación de actividades de aprendizaje en Cibermutua. Revista de investigación, Desarrollo e Innovación, 8(1), 107-120.

Beltrán -Salvo, M. P. (2016). Podcast educativo como estrategia didáctica para la comunicación y enseñanza de la ecología: un proyecto para el colegio Compañía María Seminario de Santiago. Recuperado de: https://repositorio.uc.cl/ handle/11534/21260

Bernate, J. A., García-Celis, M. F., FonsecaFranco, I. P., \& Ramírez-Ramírez- N. E. (2020). Prácticas de enseñanza y evaluación en una facultad de educación colombiana. Revista de Investigación, Desarrollo e Innovación, 10 (2).

Carceller-Cobos, C. (2016). La gamificación en aplicaciones móviles ecológicas: análisis de componentes y elementos de juego. Sphera Publica, 1(16), 95-113. Recuperado de: http://193.147.26.137/ index.php/sphera-01/article/view/280/249

Carrión-Salinas, G. A. (2017). Gamificación en educación primaria. Un estudio piloto desde la perspectiva de sus protagonistas, (Tesis de maestría, Universidad Internacional de Andalucía). Recuperado de: https://repositorio.biblioteca.unia.es/ handle/10334/3840

Corchuelo-Rodriguez, C. A. (2018). Gamificación en educación superior: experiencia innovadora para motivar estudiantes y dinamizar contenidos en el aula. Edutec. Revista Electrónica De Tecnología Educativa, (63), 29-41.

Fernández-Pampillón, A., Domínguez-Romero, E., \& Armas-Ranero, I. (2012). CODA: Herramienta de Evaluación de la Calidad de Objetos de Aprendizaje. Universidad Complutense de Madrid. Recuperado de: https://eprints.ucm.es/12533/1/

COdAv1_1_07jul2012.pdf

Garzón-Saladen, Á., \& Romero-González, Z. (2018). Los modelos pedagógicos y su relación con las concepciones del derecho: puntos de encuentro con la educación en derecho. Revista de Investigación, Desarrollo e Innovación, 8(2), 311-320.

Hernández-Díaz, J. M. (2014). Educación ambiental y vida sostenible en la Historia. Historia y Presente de la Educación Ambiental: Ensayos con perfil iberoamericano, 9-23. Recuperado de: https://dialnet.unirioja.es/servlet/ articulo?codigo $=4994894$

Hernández-Gil, C., \& Jaramillo-Gaitán, F. A. (2020). Laboratorio de innovación social: hibridación creativa entre las necesidades sociales y las experiencias significativas de los estudiantes de administración de empresas. Revista de Investigación, Desarrollo e Innovación, 10 (2).

Jiménez-Espinosa, A. (2019). La dinámica de la clase de matemáticas mediada por la comunicación. Revista de Investigación, Desarrollo e Innovación, 10 (1), 121-134.

Ley $N^{\circ} 115$. Por la cual se expide la ley general de educación, Colombia, 8 de febrero de 1994.

Lozano-Cruz, E., \& Moreno-Baquero, M. (2014). Aula virtual para la enseñanza de los conceptos estructurantes en ecología para la práctica docente. Recuperado de: http://repository.pedagogica.edu.co/ handle/20.500.12209/1783

Lozano-Guzmán, S. L., Bosque-Suárez, R., \& Osorio-Abad, A. (2019). La educación ambiental en el marco de la revolución científico-técnica: una necesidad actual en 
el contexto educativo colombiano. Varona. Revista Científico Metodológica, (68), e22. Recuperado de: http://scielo.sld.cu/ scielo.php?script=sci_arttext\&pid=S1992$82382019000100022 \&$ lng $=$ es\&tlng=es.

Malacalza, L. (2013). Ecología y Ambiente. AUGM Comité de Medio Ambiente Serie Monográfica Sociedad y Ambiente: Reflexiones para una nueva América Latina. Monografía № 2. p. 28.

Mercado-Ramos, V. H., Zapata, J., \& Ceballos, Y. F. (2015). Herramientas y buenas prácticas para el aseguramiento de calidad de software con metodologías ágiles. Revista de Investigación, Desarrollo e Innovación, 6(1), 73-83.

Ministerio de Educación Nacional de Colombia, MEN. (2017). Guía de Fortalecimiento Curricular. Siempre Día e. 25-26. Recuperado de: http://aprende. colombiaaprende.edu.co/sites/default/ files/naspublic/guia_fortalecimiento_ curricular.pdf

Niño-Vega, J. A., \& Fernández- Morales, F. H. (2019). Una mirada a la enseñanza de conceptos científicos y tecnológicos a través del material didáctico utilizado. Revista Espacios, 40 (15). Recuperado de: http://www.revistaespacios.com/ a19v40n15/19401504.html

Niño-Vega, J. A., Fernández-Morales, F. H., \& Duarte, J. E. (2019). Diseño de un recurso educativo digital para fomentar el uso racional de la energía eléctrica en comunidades rurales. SABER, CIENCIA Y Libertad, 14(2), 256-272.

Niño-Vega, J. A., Martínez-Díaz, L. Y., Fernández-Morales, F. H., Duarte, J. E., Reyes-Caballero, F., \& Gutiérrez-Barrios, G. J. (2017). Entorno de aprendizaje para la enseñanza de programación en Arduino mediado por una mano robótica didáctica. Revista Espacios, 38 (60), 23. Recuperado de: http://www.revistaespacios.com/ a17v38n60/17386023.html

Ordóñez-Ortega, O., Gualdrón-Pinto, E., \& Amaya-Franky, G. (2019). Pensamiento variacional mediado con baldosas algebraicas y manipuladores virtuales. Revista de Investigación, Desarrollo e Innovación, 9 (2), 347-362.

Orhan-Göksün, D., \& Gürsoy, G. (2019). Comparing success and engagement in gamified learning experiences via Kahoot and Quizizz. Computers \& Education, 135, 15-29. Doi: https://doi.org/10.1016/j. compedu.2019.02.015.

Palanca-Climente, M. \& Ramos-Castillo, A. (2018). La gamificación en el aula E/ LE multigeneracional: la «habitación de escape» como modelo de propuesta didáctica.

Peláez-López, R. M., Alvarado-Peláez, J. A., Zambrano-Peláez, M. J., \& LaraVásconez, C. B. (2020). Lineamientos pedagógicos para aplicar TICS y EVEA en Instituciones Educativas de Educación Básica y Bachillerato en GuayaquilEcuador. Revista Científica Ecociencia, 7, 1-14. Recuperado de: http://revistas. ecotec.edu.ec/index.php/ecociencia/ article/view/319

Rivera-Guerrero, M. A., Guadrón-Guerrero, O. E., \& Torres-Chávez, I. (2020). Detección de pesticidas en el durazno (prunus pérsica) mediante una nariz electrónica. Revista de Investigación, Desarrollo e Innovación, 10 (2).

Ruiz-Macías, E., \& Duarte, J. (2018). Diseño de un material didáctico computarizado para la enseñanza de Oscilaciones y Ondas, a partir del estilo de aprendizaje de los 
estudiantes. Revista de Investigación, Desarrollo e Innovación, 8(2), 295-309. doi: $\quad$ https://doi.org/10.19053/20278306. v8.n2.2018.7966

Sarmiento-Medina, P. J. (2013). Bioética ambiental y ecopedagogía: una tarea pendiente. Acta bioéthica, 19(1), 29-38. Doi: $\quad$ http://dx.doi.org/10.4067/S1726569X2013000100004

Sepúlveda-Gallego, L. E. (2014). Una propuesta educativo-ambiental para Colombia. Historia y Presente de la Educación Ambiental: Ensayos con perfil iberoamericano, 145-162. Recuperado de: https://dialnet.unirioja.es/servlet/ articulo? codigo $=4994894$

Toda, A. M., Da Silva, A. P., \& Isotani, S. (2017). Desafios para o Planejamento e Implantação da Gamificação no Contexto Educacional. Recuperado de: https://seer. ufrgs.br/renote/article/view/79263/0

Valda-Sánchez, F., \& Arteaga-Rivero, C. (2015). Diseño e implementación de una estrategia de gamificación en una plataforma virtual de educación. Fides et Ratio - Revista de Difusión cultural y científica de la Universidad La Salle en Bolivia, 9(9), 65-80. Recuperado de: http:// www.scielo.org.bo/scielo.php?script=sci arttext\&pid=S2071-081X2015000100006 \&lng $=$ es\&tlng=es.

Vargas-Vargas, N. A., Niño-Vega, J. A., \& Fernández-Morales, F. H. (2020). Aprendizaje basado en proyectos mediados por tic para superar dificultades en el aprendizaje de operaciones básicas matemáticas. Revista Boletín Redipe, 9(3), 167-180. https://doi.org/10.36260/ rbr.v9i3.943
Villafrades-Torres, R. (2017). La biodiversidad en Colombia: su importancia y amenazas. Recuperado de: https://www.oei.es/ historico/divulgacioncientifica/?Labiodiversidad-en-Colombia-suimportancia-y-amenazas

Zepeda-Hernández, S., Abascal-Mena, R., \& López-Ornelas, E. (2016). Integración de gamificación y aprendizaje activo en el aula. Ra Ximhai, 12 (6), 315-325. Recuperado de: https://www.redalyc.org/ articulo.oa?id=461/46148194022 